\title{
O CAPITAL POLÍTICO DOS RISCOS ECONÔMICOS $^{1}$
}

Cícero Oliveira $(\mathrm{UFG})^{2}$

cjosinaldo@hotmail.com

Resumo: A análise sociológica a respeito de algumas das mais importantes implicações do recente sistema capitalista flexível de nenhum modo erra alvo quando vincula o problema geral da instabilidade sistêmica ao descontrole das condições de vida, aos riscos sociais (a que esse descontrole se prende) e à promoção de uma mentalidade de curto prazo. Afinal, estes são fenômenos testemunhados no âmbito do trabalho em particular, e do domínio político de modo geral. Ao lado da ciência e da tecnologia a economia é um dos principais fatores modernos que institucionalizam o risco em escala social. Para a nossa abordagem, desenvolvida com bases nos pensamentos de Ulrich Beck, Zygmunt Bauman e Richard Sennett, o decisivo é que para além de oportunidades de negócio os riscos econômicos definem as mais novas atribuições do âmbito político socialmente deslocado pelo processo de divórcio com o poder.

Palavras-chave: política; economia; capitalismo flexível; risco.

Já faz muito tempo que filósofos, sociólogos e analistas sociais em geral recorrentemente destacam no capitalismo a capacidade inelutável de extensão de seu domínio. Sem meias palavras, a conversão de riscos sociais em oportunidades de negócios é o mais recente, dramático e eloquente testemunho disso. Na verdade, uma das estratégias capitalistas votadas à extensão de seu domínio é particularmente

\footnotetext{
${ }^{1}$ Recebido em: 31-03-2015/Aprovado em: 08-06-2015/Publicado on-line: 31-08-2015.

${ }^{2}$ Cícero Oliveira está em estágio pós-doutoral em filosofia na UFG, Goiânia, GO, Brasil.
} 
notável na era da consumptividade em que mesmo as mazelas socais mais dramáticas e ameaçadoras são comutadas em bens de consumo tornando-se oportunidades para big business. Para Ulrich Beck a mercantilização do risco e do medo é algo que em todas as suas manifestações está cada vez mais presente nas sociedades como um todo, como um aspecto típico dos tempos presentes ${ }^{3}$.

Tanto quanto o episódio referido por Zygmunt Bauman, em que George W. Bush no primeiro pronunciamento endereçado aos americanos imediatamente após os atentados de 11 de setembro pede à todos que retomem a vida normal regressando às compras ${ }^{4}$, a conversão dos riscos em objeto de consumo não só denuncia a privatização da condição social de segurança, como também testemunha mais uma vez e de forma eloquente o nível do compromisso social com o consumo na atualidade.

Os medos ou riscos sociais, como prefere Beck, são hoje de fato grandes oportunidades de mercado. Por serem social e continuamente produzidos, definidos, divulgados e comercialmente explorados eles geram necessidades crescentes e insaciáveis de segurança. Não bastasse a produção de riscos ser algo inesgotável, já que hoje é inseparável do funcionamento regular das sociedades complexas, ele ainda pode ser destacado, exagerado e manipulado pelas meios de comunicação de massa. Além do que, especialmente confi-

\footnotetext{
3 "Os riscos não são nesse caso apenas riscos, são também oportunidades de mercado. É precisamente com o avanço da sociedade de risco que se desenvolvem como decorrência das oposições entre aqueles que são afetados pelos riscos e aqueles que lucram com eles. Da mesma forma, aumenta a importância social e política do conhecimento, e consequentemente do acesso aos meios de forjar o conhecimento (ciência e pesquisa) e disseminá-lo (meios de comunicação de massa). A sociedade do risco é, nesse sentido, também a sociedade da ciência, da mídia e da informação. Nela, escancaram-se assim novas oposições entre aqueles que produzem definições de risco e aqueles que consomem." (BECK 2010, p. 56. Grifos do autor).

${ }^{4}$ Cf. Bauman, 2011b.
} 
ada à ciência e à política, a definição variável dos riscos ou das situações de riscos geram necessidades inteiramente novas. Uma vez cientifizados, avaliados e politicamente afirmados os riscos se tornam mais suscetíveis às demandas comerciais.

É verdade que na sociedade de risco e de medo generalizados a segurança é uma mercadoria preciosa e cara, especialmente quando a política é negligente e abandona ao indivíduo a tarefa de resolver de modo particular ou biográfico um problema socialmente constituído. Como toda mercadoria cara a segurança é um objeto cujo acesso permite ao analista social identificar dois grupos distintos de indivíduos: os que consomem e os que somente sonham em poder consumir. O primeiro grupo é responsável pelo surgimento do que Zygmunt Bauman chama de "guetos voluntários", isto é, os condomínios fechados de alto luxo; os espaços vetados e claramente destinados a segregar, a excluir e a dividir os de dentro e os de fora. Aqueles são os "cidadãos da primeira fila”, estes são os "cidadão da última fila", os sem recursos que podem ser especialmente localizados nos guetos involuntários: nos bairros difíceis, desestruturados e acima de tudo perigosos a que estão condenados a residir.

A urbes (cidade) que um dia foi cercada por muros em nome da segurança comum de seus cidadãos é hoje a mais fatal das fontes de periculosidade. Quer o perigo seja real, quer seja aparente, as cidades agora mais do que nunca são projetadas para segregar. A atual luta pela sobrevivência no cenário urbano aposta nas dispendiosas e seletivas estratégias da separação e da distância, mas também na "estética da segurança” pela qual são concebidas as pequenas fortalezas fixas (casas) e móveis (carros blindados), em todo caso 
equipadas com dispositivos de segurança high tech. Tais atitudes que tomamos frente aos medos socialmente gerados, mais alimentam a indústria do medo do que curam a ansiedade que nos atormenta .

Ao lado da ciência e da tecnologia a economia é um dos principais fatores modernos que institucionalizam o risco em escala social ${ }^{5}$. Para o nosso contexto o decisivo é que para além de oportunidades de negócio os riscos, especialmente os econômicos, definem as mais novas atribuições do âmbito político socialmente deslocado pelo processo de divórcio com o poder. Em virtude disso, o controle do presente e o planejamento do futuro é algo que por intervenção da economia flexível se acha em crise tanto no mundo trabalho quanto no cenário político. Nenhum dos mecanismos de controle ou salvaguarda importantes nas condições atuais estão sob a jurisdição, quanto mais sob o

\footnotetext{
${ }^{5}$ Não obstante o foco deliberado que nosso estudo confere aos ricos oriundos de processos econômicos globalizados e emancipados, a modernidade avançada se define para Beck a partir de uma nova, ampla e multifacetada relação com o risco. Este é aliás o sentido extado da expressão que intitula o famoso livro do sociólogo alemão: Sociedade de risco - rumo a uma outra modernidade. Isso considerando que mais que "resíduo tradicional" da modernização o risco se torna o próprio produto desse processo: "Na modernidade desenvolvida, que surgiu para anular as limitações impostas pelo nascimento e para oferecer às pessoas uma posição na estrutura social em razão de suas próprias escolhas e esforços, emerge uma novo tipo de destino 'adscrito' em função do perigo, do qual nenhum esforço permite escapar. Este se assemelha mais ao destino testamental da Idade Média que às posições de classe do século XIX. Apesar disso, não se vê nele a desigualdade dos estamentos (nem grupos marginais, nem diferença entre campo e cidade ou de origem nacional ou étnica, e por aí afora). Diferente dos estamentos ou das classes, ele não é uma 'resíduo tradicional', mas uma produto da modernidade, particularmente em seu estágio de desenvolvimento mais avançado. Usinas nucleares - o auge das forças produtivas e criativas humanas, converteram-se, desde Chernobyl, em símbolos de uma moderna Idade Média do perigo. Elas designam ameaças que transformam o individualismo moderno, já levado por sua vez ao limite, em seu mais extremo contrário." (BECK 2010, p. 8. Grifos do autor). Também Antony Giddens, em Modernidade e identidade, apresenta uma noção semelhante de sociedade de risco: "A modernidade reduz o risco geral de certas áreas e modos de vida, mas ao mesmo tempo introduz novos parâmetros de risco, pouco conhecidos ou inteiramente desconhecidos em épocas anteriores. Esses parâmetros de riscos de alta consequência, são derivados do caráter globalizado dos sistemas da modernidade. $\mathrm{O}$ mundo moderno tardio - o mundo que chamo de alta modernidade - é apocalíptico não porque se dirija inevitavelmente à calamidade, mas porque introduz riscos que gerações anteriores não tiveram de enfrentar." (GIDDENS 2002, p. 11-12)
} 
controle dos indivíduos e mesmo das coletividades. A inexorabilidade da economia flexível ou dos processos econômicos de desregulamentação nos lança num estado de precariedade estrutural em que o futuro, antes atrelado às esperanças confiadas ao trabalho e ao empreendimento políticos, agora mais nos aterroriza do que nos acalma. E esta inexorabilidade, "longe de ser o produto de inescrutáveis e invencíveis leis da Natureza ou da pecaminosa mas irredutível natureza humana, é em grande medida produto do que só pode ser chamado de economia política da incerteza". (BAUMAN 2000, p. 175)

A "economia política da incerteza", outro nome para a economia flexível, define as circunstâncias em que os operadores do poder extraterritorial estipulam as regras que almejam pôr fim a todas as regras das autoridades políticas locais. Sua ação essencialmente negativa não pretende substituir uma ordem por outra, visa somente o desmantelamento da ordem existente somada à garantia de que a desregulamentação política que ela empreende não se seguirá de uma nova regulamentação. Por esta razão suas medidas perseguem ao mesmo tempo o desarmamento das instituições cuja oposição pode cerrar as fronteiras capazes de obstar a livre circulação do capital de das finanças .

A consequência dessa desregulamentação política é naturalmente um estado permanente e generalizado de incerteza e instabilidade que no cenário político substitui os expedientes e controles coercitivos e as medidas de estabilidade por ajustes de flexibilização e garantias de não resistência. A mensagem de fundo da economia flexível, particularmente manifesta no mundo do trabalho, é que "todo mundo é potencialmente supérfluo ou substituível e, portanto, todo mundo é vulnerável e qualquer posição so- 
cial, por mais elevada e poderosa que possa parecer gora, é precária a longo prazo" (BAUMAN 2000, p. 175) .

Nas instituições de ponta do capitalismo flexível o trabalho, que era tradicionalmente um dos meios mais confiáveis para enfretamento da insegurança e das incertezas do futuro, não apenas torna-se ele mesmo uma fonte de angústia incapaz de resistir a qualquer sorte de planejamento, como assumiu a forma de uma estratégia recomendável (a "flexibilidade") para se ajustar à instabilidade dominante da nova economia ${ }^{6}$.

Por ação da economia flexível também a política recebe a marca de ferro do descontrole e da incerteza. Queremos destacar portanto que no espaço de transições em que a política é progressivamente expropriada do poder de decisão, sua nova função envolve mais o gerenciamento, uma espécie de tratamento clínico ou terapêutico dos incontornáveis riscos liberados por processos econômicos emancipados (e outros riscos oriundos do processo de modernização de que aqui não trataremos), do que a gestão exclusiva da sociedade a partir do controle efetivo das condições de vida - que caracterizou a modernidade política até a recente erosão do Estado social. O ponto central da presente discussão envolve o fato, exemplarmente referido por Beck, de que "os riscos converteram-se no motor da autopolitização da

\footnotetext{
${ }^{6}$ Desenvolvemos esse argumento no texto "Um novo trabalho para um novo capitalismo: de Max Weber a Richard Sennett". Neste estudo sobre o descontrole das condições sociais nascido no domínio econômico moderno examinamos algumas das consequências do expediente econômico de "flexibilização". Procuramos destacar as medidas com que o sistema econômico, em função da livre circulação do capital no espaço global, pretende suprimir toda forma de planejamento, controle e circunspeção a longo prazo, especialmente no que concerne ao mundo do trabalho. A "ordem do descontrole" é, como procuramos argumentar, um fenômeno coevo à desregulamentação econômica do trabalho e da política. É pela precarização de duas das principais atividades às quais a modernidade confiou o planejamento das trajetórias de vida, que a flexibilidade gera descontrole e sobrecarrega de riscos e instabilidade as trajetórias individuais e coletivas.
} 
modernidade na sociedade industrial - e mais: com eles, alteram-se conceito, lugar e meios da 'política'." (BECK 2010, p. 275. Grifos do autor)

Nesse caso, para além de um compromisso profundo e sem precedentes com a promoção do consumo e do crescimento econômico, é também por um tratamento e por uma capitalização dos riscos autogerados (por uma abordagem dos riscos como justificativa para a gestão mais interessada na segurança do que na configuração das condições de vida que agora começa a escapar ao seu controle), que a política reintegra o sistema social no mesmo instante em que dele se despede pelo divórcio com o poder.

O jogo sem regras da economia flexível (as práticas de desregulamentação) se apoia na incerteza, nos riscos e na insegurança de que ela é fonte irradiadora. No plano político, mas também nas esfera do trabalho, seu caráter coercitivo se prende antes de tudo às pressões que ela exercesse sob o amparo da noção de crescimento traduzida em imperativo econômico e meta principal no contexto de uma sociedade de consumidores ${ }^{7}$. Todavia, o controle pela incerteza e pelos riscos como base operacional do sistema flexível é particularmente profícuo aos negócios na medida em que torna supérfluos e excessivamente dispendiosos os dispositivos disciplinares. Não é que o domínio da flexibilidade aposte na antiga ética do trabalho, quando a responsabilidade pelo

\footnotetext{
${ }^{7}$ Os estudos de Richard Sennett, por exemplo, mostram que no âmbito do trabalho "o controle [do sistema flexível] pode ser estabelecido instituindo-se metas de produção ou lucro para uma ampla variedade de grupos na organização, que cada unidade tem liberdade de cumprir da maneira que julgar adequada. Essa liberdade no entanto é capciosa. É raro as organizações flexíveis estabelecerem metas de fácil cumprimento; em geral as unidades são pressionadas a produzir ou ganhar muito mais do que está em suas capacidades imediatas. As realidades de oferta e procura raramente estão em sincronia com essas metas; o esforço é para forçar cada vez mais as unidades, apesar dessas realidades, uma pressão que vem da alta administração da instituição." (SENNETT 2011, p. 65)
} 
empenho produtivo era confiada ao indivíduo autodirigido e motivado graças a uma forte formação doutrinária. Mas

No que concerne à submissão passiva às regras do jogo ou a um jogo sem regras, a incerteza endêmica de alto a baixo do escalão social é um substituto limpo, barato e altamente eficaz da regulação normativa, da censura e da vigilância. Fora os setores marginais dos excluídos e supérfluos, que têm bastante certeza de sua exclusão e inutilidade para serem receptivos à políticas da incerteza, os sistemas panópticos não são mais necessários, quer nas suas versões antigas e pesadas, quer nas novas, leves e atualizadas versões. Só a liberdade, na sua versão de mercado, pode ter a completa confiança para produzir toda a conduta humana necessária ao funcionamento normal da economia global. (BAUMAN 2000, p. 176)

A flexibilidade ou a liberdade econômica de dar as cartas, de impor, desfazer e refazer as condições essencialmente flutuantes faz da incerteza e do risco a norma que confere força à cada cartada. Com efeito, "o tempo da flexibilidade é o tempo de um novo poder. Flexibilidade gera desordem, mas não livra das limitações.” (SENNETT 2011, p. 70). Essa incerteza sistêmica, programática e metódica que impregna de riscos cada novo passo com que a nova economia se põe em movimento, é tanto mais eficiente por que se conjuga a uma impotência difusa, que incapacita indivíduos e mesmo coletividades privatizadas e inseguras (postas numa condição de risco estrutural) de agirem de modo concertado. A impotência que a era da flexibilidade aciona se torna tanto mais profunda na proporção direta em que se estende a descrença na efetividade de qualquer ação transformadora .

A privatização como expediente econômico que associa incerteza, risco e impotência implica a incapacidade de reconduzir ao plano das questões coletivas tudo que agora é sistematicamente tratado como uma preocupação privada, 
isto é, de responsabilidade exclusivamente individual, cuja resolução está a cargo de cada um. Ao término do projeto/processo econômico de desregulamentação da política resta o fato de que questões coletivas resultam precisamente no que tende a desaparecer sob o domínio da flexibilidade .

Como a incerteza endêmica do mundo contemporâneo enraíza-se no poder global contra o qual a política restrita aos domínios da localidade se mostra impotente ou incapaz de opor qualquer resistência séria, é natural e esperável, como disse Ulrich Beck, a tradução de problemas sistêmicos em fracasso pessoal. A metamorfose da causalidade externa em culpa própria, da precariedade estrutural em problema particular, é o expediente com que "problemas sistêmicos se convertem em fracassos pessoais e se decompõem politicamente." (BECK 2010, p. 109) .

Essa responsabilização individual por problemas estruturais supõe a dissolução da condição que nos permite identificar o local de onde estes problemas emergem no mundo humano. A interdição da condição de fenômeno externo ou econômico, de causa comum e localizável é a própria negação da significação coletiva implícita em toda questão política .

$\mathrm{O}$ expediente que comuta causalidade externa em culpa própria é particularmente observável no âmbito do desemprego estrutural e da pobreza: "a precariedade que ao longo de contínuas tentativas se converte em desemprego duradouro é", como afirma Beck, "a via crucis da autoconfiança. $\mathrm{Na}$ contínua exclusão do possível, o desemprego, algo externo portanto, penetra passo a passo na pessoa, convertendo-se num atributo seu." (BECK 2010, p. 139. Grifos do autor).

Nas condições de trabalho marcadas pela flexibilidade e 
pela privatização da precariedade econômica as pessoas são sobrecarregadas com a instabilidade e o desemprego em massa como se fossem um destino pessoal. Os afetados têm de lidar individualmente com um fato cujo caráter social e sistêmico é vaga e inocuamente entrevisto apenas a partir das análises estatísticas. A efetiva restauração do fenômeno como questão social e política é uma possibilidade esgotada por sua fragmentação no âmbito da responsabilidade individual. "A unidade referencial atingida pelo raio do desemprego e da pobreza já não é o grupo, a classe ou a camada social, mas o individuo de mercado em suas circunstâncias específicas" (BECK 2010, p. 134. Grifos do autor).

Nesse caso, a ênfase sobre o risco de desemprego se descola das condições flutuantes do mercado de trabalho para a inabilidade dos que não desenvolvem a aptidão potencial e não se fazem flexíveis; dos que se prendem à rotina, perícia e burocracia que a nova economia identifica com as práticas deletérias próprias dos antigos e obsoletos dispositivos de estabilidade. Num cenário em que as condições para o emprego são arrancadas do mundo econômico e lançadas para o interior das "qualidades" pessoais (ser flexível), o desemprego traduz a inadaptabilidade de individualidades excessivamente rijas, presas à rotinas, tarefas e compromissos de longo prazo. Em resumo, a indisponibilidade para o risco e para a adaptabilidade, a própria negação das virtudes cardeais do trabalho que emerge, indica a incapacidade geral de lidar com o desafio que a economia emancipada alçou à condição de necessidade diária a ser enfrenta pelas massas.

Numa veia mais caseira, os autores de Upsing the Individual and Downsizing Corporation invocam a imagem do trabalho sendo continuamente trocado de vaso, como uma muda de planta, e do trabalhador 
como jardineiro. A própria instabilidade das organizações flexíveis impõe aos trabalhadores a necessidade de "trocar de vasos", isto é, correr riscos, com seu trabalho. Esse manual de negócios é típico de muitos outros no fazer dessa necessidade uma virtude. (SENNETT 2011, p. 94)

Com o trabalho flexível em particular, mas também com a política de co-operação econômica em geral, os riscos econômicos atravessam e condicionam a vida social e tornam-se normais e comuns. É nesse contexo social de instabilidade que as ofertas (comerciais) e as promessas (políticas) de segurança avançam em conjunto com os riscos. Não surpreende assim que na sociedade de risco analisada pelas mais variadas abordagens sociológicas o "contraprojeto normativo, que lhe serve de base e de impulso, é a segurança." (BECK 2010, p. 59. Grifos do autor) .

É neste contraprojeto característico de uma sociedade de risco que a política em via de se tornar supérflua, em função de forças econômicas globais, tende a se reencontrar no sistema social. Na sociedade da incerteza, do medo e do risco endêmicos, a segurança emerge como uma força política extraordinária. Ao lidar com o problema da insegurança no sentido de gerir e remediar (portanto não mais no sentido de fazer o controle, reprimir ou combater em sua fonte originária) a esfera política se ajusta, integra e coopera com o processo de transição que redefine a função política do econômico.

Essa definitiva simbiose entre Estado e mercado deflagra nos assuntos humanos processos econômicos que, destituídos de controle, comportam riscos potenciais essencialmente instáveis, vagos e por isso mesmo temíveis. A despeito do caráter indeterminável e difuso do temor, é como risco geral de exclusão, superfluidade econômica e 
vulnerabilidade social que se ressente a contingência e as pressões da esfera econômica. $\mathrm{O}$ medo difuso que o Estado social prometeu extirpar agora espreita os indivíduos impotentes a partir de uma renitente e angustiante ameaça de exclusão normalizada como expediente operacional do sistema flexível .

[...] Conseguir se manter em lugar legítimo e digno na sociedade humana e evitar a ameaça da exclusão - é uma tarefa deixada às habilidades e aos recursos de cada indivíduo, por sua conta. Isso significa correr riscos enormes e sofrer com a angustiante incerteza que empreitadas como essas inevitavelmente incluem. O medo que o Estado social prometeu extirpar retornou com uma vingança. A maioria de nós, da base ao topo da pirâmide social, hoje teme a ameaça, embora vaga, de ser excluído, de se provar inadequado para os desafios, de ser desprezado, de ter sua dignidade negada e humilhada." (BAUMAN 2009, p. 89)

Dissemos acima que a sociedade de risco e dos medos de raízes econômicas gera mais do que rendimentos pecuniários. Não fosse pela capitalização dos riscos, pelo tipo de rentabilidade que eles asseguram à esfera política (enredada na promoção do crescimento econômico) ela restaria deslocada do trato com as condições da vida social que a rigor ela já não governa. As ações restritivas com que o Estado de bem-estar, enleado ao poder, exercia o controle do risco social foram substituídas pelas práticas que indicam a posição secundária da política restrita ao manejo, isto é, à necessidade de lidar com processos compulsórios que ela não inicia, não pode prever e nem tampouco consegue controlar. A economia livre abandona à política, como forma de reaver sua autoridade posta em crise, um novo tipo de relação com a segurança .

$\mathrm{Na}$ análise da dinâmica global em torno da qual giram as principais cidades do mundo, e graças à sua grande capa- 
cidade de tornar legível os menores aspectos cotidianos da existência, Bauman julgou detectar os sinais de um futuro que se aproxima. Em Confiança e medo na cidade o autor sustenta que na fase histórica iniciada nos últimos decênios do século XX, as chamadas "cidades globais" por razões diversas se tornaram o epicentro e, para o analista social, o próprio observatório das mudanças provocadas pelo processo desregulamentação .

Uma parte bastante significativa dos medos sociais hodiernos, conforme Bauman, resulta tanto do descontrole estatal sobre os processos econômicos que perpassam a sociedade, quando do colapso do sistema de proteção e solidariedade coletiva simbolizado pelo Estado social que esses mesmos processos acabam por sepultar. O determinante é que "a dissolução da solidariedade representa o fim do universo no qual a modernidade sólida administrava o medo" ${ }^{8}$ (BAUMAN 2009, p. 20).

Quando "o Estado lavou as mãos sobre a vulnerabilidade e a incerteza provenientes da lógica (ou falta de lógica) do livre mercado" e, em seu encalço, a esfera econômica forjou a "condição que define como falha e problema individual, - uma questão para indivíduos enfrentarem e com a qual lidarem pelo uso dos recursos que disponham individualmente -" (BAUMAN 2011b, p. 112), as cidades globais, que são os próprios epicentros das transformações em curso, passaram a registrar certos fluxos e deslocamentos populacionais. Mais do que refletir a verticalização crescente das disparidades, os fluxos característicos das cidades de

\footnotetext{
${ }^{8} \mathrm{O}$ colapso da solidariedade social, no que possui de decisivo para o advento de um medo vago e difuso como fenômeno de massa, é para Bauman uma ocorrência abrangente que envolve também a crise das associações, sindicatos e outros laços artificiais com que a modernidade conjugou forças individuais para o combate das condições de risco.
} 
ponta do capitalismo flexível supõem a rápida escalada social do risco e também uma forma específica de geri-lo.

Nas grandes áreas urbanas, referenciais no que concerne as funções mais avançadas do capitalismo flexível, as aferradas e intensas pressões econômicas que no plano político desregulamentam o mercado de trabalho e desmantelam o sistema de proteção social também disponibilizaram novas e extraordinárias oportunidades de investimentos mediante a ampliação de certos mercados. Desde o início da expressiva influência dessa variável econômica no fenômeno da verticalização social, as cidades globais se tornaram palco de deslocamentos populacionais cujos resultados foram igualmente significativos para o caráter difuso da insegurança e do risco social.

O caráter obstinadamente ostensivo do fenômeno não poderia fazê-lo passar despercebido ao mais comum dos observadores e nem tampouco à qualquer estudo social dos fluxos urbanos. A despeito dos vários fatores que certamente merecem ser computados como causa, é também especialmente sob a moção da insegurança e do risco que se desenrolam dois movimentos urbanos estreitamente articulados, constitutivos das marcas urbanas das desigualdades e das diferenças sociais .

De um lado os deslocamentos dos grandes centros urbanos registram o advento de enclaves que segregam os cidadão da "primeira fila", afinados com as condições de extraterritorialidade do espaço global. Entre os que nas cidades do medo se colocam sob a proteção dos privados e seletivos esquemas de segurança - especialmente os "bairros" próprios -, estão aqueles que se reorganizam segundo uma lógica de rede norteada pelas diretrizes dos poderes globais, em mobilidade absoluta. Do outro lado da segregação, ago- 
ra em sua versão passiva (no sentido dos que são abandonados à própria sorte), estão os cidadãos da "segunda fila"; duplamente enraizados nos limites da localidade onde são deixados para suportar as mais negativas consequências das mudanças, apartados e marcados com o emblema da marginalidade, da superfluidade e da exclusão.

Sob o influxo irrestrito do livre mercado, na medida em que aprofunda as distâncias sociais (ao mesmo tempo em que solapa as instituições da solidariedade social), as cidades globais tornaram-se espaços de insegurança e medo generalizados. E estes, por sua vez, se tornam tanto mais difusos em virtude do aprofundamento das desigualdades mas também das diferenças, mais do que nunca evidenciadas pelas marcas urbanas da segregação. Tal separação, embora se origine de um estado de coisas em que a insegurança tornou-se estrutural, fomenta ainda mais a sensação compartilhada de risco iminente.

Sob a moção comum do medo encontram-se duas categorias de indivíduos que apenas aparentemente ocupam o mesmo espaço urbano. A mobilidade plena dos globalizados ou extraterritoriais, interligados em rede aos poderes realmente poderosos e desconectados do próprio lugar em que residem, sugere a distância abissal que os separa dos que estão radicados nos confins da localidade, da qual os recursos próprios (os únicos com que podem contar em face de uma política impotente) não lhes permitem fugir. Como disse Bauman, para além do divórcio entre poder e política, "localização" e "extraterritorialidade" também traduzem dois planos de existência urbana em total assimetria e descompromisso .

A mobilidade adquirida por "pessoas que investem" - aquelas com capital, com o dinheiro necessário para investir - significa uma nova 
desconexão do poder face a obrigações, com efeito uma desconexão sem precedentes na sua radical incondicionalidade: obrigações com os empregados, mas também com os jovens e fracos, com as gerações futuras e com a auto-reprodução das condições gerais de vida; em suma, liberdade face ao dever de contribuir para a vida cotidiana e a perpetuação da comunidade. Surge uma nova assimetria entre a natureza extraterritorial do poder e a contínua territorialidade da "vida como um todo" - assimetria que o poder agora desarraigado, capaz de se mudar de repente ou sem aviso, é livre para explorar e abandonar às consequências dessa exploração. Livrar-se da responsabilidade pelas consequências é o ganho mais cobiçado e ansiado que a nova mobilidade propicia ao capital sem amarras locais, que flutua livremente. Os custos de se arcar com as consequências não precisam agora ser contabilizados no cálculo da "eficácia" do investimento. (BAUMAN 1999, p. 16-17)

As conexões globais que influem na vida urbana e deixam aos cuidados da localidade a tarefa de lidar com os resultados sociais das mudanças que elas provocam, implicam a necessidade de administração local/política dos problemas com que o mercado livre de amarras não se compromete. É nessa dinâmica estrutural a que a localidade está sujeita, que a política, desregulamentada pelo novo sistema econômico, a um só tempo gere, especula e capitaliza os riscos cuja origem ela não já não pode conter .

Os recursos penosamente escassos e inadequados de que a política (confinada ao âmbito da localidade que ela não mesma governa) se serve para moderar a insegurança extraterritorial, não podem e nem mesmo pretendem localizar e alcançar o centro a partir do qual se processão as transformações fundamentalmente fora de controle. No interior da localidade de onde são operados, os recursos políticos tendem fatalmente a padecer de impotência: uma débil capacidade de agir eficientemente no que se refere ao drama provocado pelos poderes globais. $O$ plano local a que se restringem as intervenções do empenho político, 
embora seja o cenário em que se localizam as questões sobre as quais se pode fazer alguma coisa, faz fronteira com as determinações supralocais para as quais, admite-se, não há alternativas ${ }^{9}$.

A insuficiência e a inadequação dos recursos políticos indicam que, independente do que se faça, os processos econômicos emancipados seguirão seu curso agora reconhecidamente inexorável nos assuntos humanos. Os aspectos combatidos e combatíveis no plano da localidade poucas vezes ou quase nunca coincidem com a fonte de ansiedades e de temores. Independentemente do quão bemsucedidas possam ser a investidas do Estado contra as ameaças que a mídia torna públicas, as fontes primárias e autênticas, as causas endêmicas do risco e do medo restarão intactas.

O mais grave é que nas novas atribuições gerenciais que a política desempenha relativamente aos riscos, há igualmente uma evidente disposição à reduzir o problema da insegurança social à uma questão individual particularmente assemelhada às estratégias de marketing mobiliário. É que em ambos os casos, comercial ou politicamente, nas autênticas ou supostas ameaças inerentes às cidades do risco e do medo, o clima geral de insegurança é no mais das vezes tratado como uma questão referente à segurança pessoal ${ }^{10}$.

\footnotetext{
9 "As forças políticas que poderiam atacar a insegurança global na fonte não chegam nem perto do nível de institucionalização alcançado por aquelas forças econômicas (capital, finanças e comércio) que são a fonte da insegurança global. Não há nada que se compare à riqueza, determinação e eficácia do Fundo Monetário Internacional, O Banco Mundial e a rede cada vez mais cerrada do sistema mundial de bancos e investimentos e compensação." (BAUMAN 2000, p. 198)

${ }^{10}$ Está claro pela arquitetura do medo que reconfigura as cidades que "o fator medo aumentou, como [também] demonstram os incrementos dos mecanismos de tranca para automóveis, as portas blindadas e os sistemas de segurança; a popularidade das gated and secure communities para pessoas de todas as idades e faixas de renda; e a vigilância crescente dos locais públicos, para não falar dos contínuos alertas de perigo por parte dos meios de comunicação de massa." (BAUMAN 2009, p. 40-41)
} 
A privatização do risco social endêmico, sua conversão comercial e especialmente política em questão de segurança pessoal, mostra que "assim como o dinheiro líquido disponível para investimentos de todo tipo, o 'capital do medo' pode ser transformado em qualquer tipo de lucro político ou comercial” (Bauman, 2009, p. 55). Na era da economia flexível, fonte de instabilidade e insegurança globais, a gestão política do risco o encerra no domínio da localidade, que como problema de segurança pessoal é explorado tanto pelo mercado quanto pelo marketing dos projetos políticos de campanhas eleitorais. Mais uma vez o paralelo é inevitável: o problema da segurança pessoal (em que se comuta a questão do risco social) possui um alcance cuja abrangência vai das vantagens destacadas nos produtos do marketing imobiliário até à ênfase política sobre "lei e ordem", particularmente sublinhadas como promessas de segurança pessoal ${ }^{11}$.

O gerenciamento ou o empenho político em reduzir e dissolver o problema do risco difuso a uma questão de segurança pessoal é desesperado e ao mesmo tempo tentador. Desesperado porque a crise do controle político associada ao colapso do sistema de proteção social resulta, como observa Beck, na expectativa de que os indivíduos privatizados e impotentes busquem soluções biográficas para contradi-

\footnotetext{
${ }^{11}$ Em Vida a crédito Bauman afirma o seguinte: "o Estado contemporâneo - rescindindo sua postura programática anterior, de caráter terapêutico, em relação às consequências da insegurança produzida pelo mercado, e, no sentido contrário, proclamando a perpetuação e intensificação da insegurança como missões de todo poder político preocupado com o bem-estar de seus súditos deve buscar outras variedades não econômicas de vulnerabilidade e insegurança nas quais sustentar sua legitimidade. Essa alternativa parece ter sido alocada (talvez em sua forma mais espetacular, porém de modo algum exclusiva, pelo governo americano) na questão da segurança pessoal: ameaças ao corpo, aos bens e aos hábitats dos seres humanos, perigos provenientes de atividades criminosas, condutas antissociais por parte 'da subclasse' e, mais recentemente, terrorismo internacional." (BAUMAN 2010b, p. 40)
} 
ções sistêmicas que a política não pode alcançar. É tentador porque, sob o império do medo em que a segurança se torna o contraprojeto normativo da vida social, a política tende a especular com o próprio medo cofiado aos seus cuidados clínicos pouco eficientes.

Não podendo fazer nada de significativo para aplacar, quanto mais para eliminar a incerteza e a angustia - os produtos básicos da globalização - os poderes do Estado se voltam para objetivos alcançáveis capazes de restaurar sua legitimidade perdida. No mesmo movimento em que abandona a maior parte de suas funções econômicas e sociais aos poderes globais, a política se volta para o manejo da insegurança (enquanto política de segurança) como eixo de uma estratégia para reaver diante dos cidadãos sua importância na tarefa de proteção social .

Ocorre que a busca política de escoadouros de medos e ansiedades por alvos à mão, recaem frequentemente sobre os refugos humanos das forças globais: refugiados, pessoas em busca de asilo político, imigrantes e toda sorte de redundantes econômicos que se encaixam perfeitamente neste papel ${ }^{12}$. É assim que, como Bauman argumenta em Vidas desperdiçadas, a política de segurança encarnada pelo Estado a serviço do crescimento econômico em descontrole, tende para a criminalização da população economicamente redundante. Neste sentido, o tratamento político dispensado aos imigrantes e refugiados econômicos é realmente paradigmático.

\footnotetext{
12 "A incerteza não pode ser difundida nem disseminada num confronto direto com outra encarnação da extraterritorialidade: a elite global que flutua além do controle humano. Essa elite é poderosa demais para ser confrontada e desafiada de modo franco, mesmo que sua localização exata fosse conhecida (o que não é). Os refugiados, por outro lado, são um alvo bastante visível, e imóvel, para o excedente de angústia”. (BAUMAN 2004a, p. 85)
} 
O influxo de recém-chegados tem recebido a culpa, de modo direto ou oblíquo, pelo aumento da inquietação e dos temores difusos que emanam de um mercado de trabalho cada vez mais precário. [...] o Estado flexionou os músculos, embora débeis e indolentes em todos os outros domínios, em plena vista do público - criminalizando as margens da população que se mostravam mais frágeis e viviam de forma mais precária, projetando política de 'mão firme' cada vez mais rígidas e severas, e lançando espetaculares campanhas contra o crime centradas no refugo humano de origem estrangeira. (BAUMAN 2004a, p. 105)

De fato, na forma terapêutica com que a política gerencia os riscos e medos "o que chama a atenção do olhar e mobiliza a imaginação é a forma como o ressentimento se dirige para os imigrantes e se torna politicamente rentável”. O Estado clínico também é aquele em que política (para além de um compromisso incondicional com o crescimento econômico) se define segundo um certo tipo de tratamento capitalizável dos riscos economicamente instalados no corpo social. Nesta dinâmica a política paradoxalmente também se lança contra as próprias vítimas da nova economia .

Diante de um eleitorado sedento de um alvo visível contra o qual possa disparar o excedente de angustia, e em nome da política de segurança que ele deseja, o Estado terapêutico em crise de legitimação trabalha com o efeito placebo: "de uma forma perversa, os imigrantes representam tudo o que gera ansiedade e desperta horror na nova variedade de incerteza e insegurança que tem sido e continua a ser induzida pelas misteriosas, impenetráveis e imprevisíveis "forças globais"' (BAUMAN 2010b, p. 90). O tratamento político dos riscos sociais, não obstante sua ineficiência real, é muitas vezes julgado segundo a severidade ou mão forte dispensada aos medos oficiais por parte dos que estão 
poder ou a ele aspiram chegar ${ }^{13}$.

Há ainda uma outra classe extremamente ampla e por isso mesmo inominável de refugos econômicos socialmente indesejáveis que, em conjunto com os estrangeiros, produz em massa a "subclasse" (underclass) comportamental ${ }^{14}$. Essa categoria populacional, embora ausente dos esquemas mentais de divisão social, é emblemática e realmente indispensável à política de segurança do Estado clínico capitalizador de riscos, que também por pressões econômicas se empenha numa sutil estigmatizarão e criminalização da pobreza e da redundância social.

Forjada nos Estados Unidos, underclass é a palavra com que ficou conhecida a faixa da população tornada econômica e socialmente supérflua no interior do sistema flexível. Subclasse não é portanto uma palavra que designa um estado de anomalia social passível de remediação, como quando nos referimos à condição de alguém se encontrar momentaneamente desempregado.

Em Vida para consumo Bauman esclarece que antes de

\footnotetext{
13 "Os imigrantes, e em particular os recém-chegados, exalam o odor opressivo do depósito de lixo que, em seus muitos disfarces, assombra as noites das potenciais vítimas da vulnerabilidade crescente. Para aqueles que os detratam e os odeiam, os imigrantes encaram - de modo visível, tangível em carne e osso - o pressentimento inarticulado, mas pungente e doloroso, de sua própria condição de descartável. Fica-se tentado a dizer que, se não houvesse imigrantes batendo às portas, eles teriam de ser inventados... De fato, eles fornecem aos governos um 'outro desviante' ideal, um alvo muito bem-vindo para 'temas de campanha selecionados com esmero'." (BAUMAN 2004a, p. 73)

${ }^{14}$ Há normalmente um amplo inventário de pessoas comprimidas no termo subclasse: "essa definição comportamental de pessoas pobres que abandonaram os estudos, não trabalham e, caso sejam mulheres jovens, têm filhos sem o benefício do casamento e vivem de previdência social. A subclasse comportamental também inclui os sem-teto, mendigos e pedintes, pobres viciados em álcool e drogas, além dos criminosos de rua. Como o termo é flexível, os pobres que vivem nos 'conjuntos habitacionais', os imigrantes ilegais e os membros de gangues de adolescentes também são muitas vezes classificados como subclasse. Na realidade, a própria flexibilidade da definição comportamental é que propicia que o termo se torne um rótulo capaz de ser usado para estigmatizar os pobres, seja lá qual for seu verdadeiro comportamento". (GANS apud BAUMAN 2008, p. 157)
} 
cair em desuso a expressão "classe trabalhadora" era própria do imaginário social que mesmo pressupondo a diferença, e até a oposição das ocupações de ricos e pobres, as concebia como complementares numa ordem social em que cada indivíduo tinha uma função definida e invariavelmente compreendida como indispensável ao sistema social. A pressuposição subjacente nesse imaginário social era a de que todos, independentemente do que possam fazer, têm um papel social a representar. Já o termo "classe baixa”, particularmente familiar à esse contexto, evoca a imagística de uma sociedade marcada pela mobilidade social em função da qual cada posição é em princípio momentânea, isto é, sujeita a mudança. Nesse contexto, "ser" da classe baixa, ainda que originariamente, não indica mais do que uma condição, concebida por todos como reversível - como a condição de desemprego -, de quem se encontrando numa posição de inferioridade pode ser capaz de subir (com esforço e sorte) para escapar à vulnerabilidade.

Subclasse, ao contrário de expressões como "classe trabalhadora" ou "classe baixa", aponta enfática e diretamente para a condição de redundância, superfluidade e vulnerabilidade radicais de pessoas que nas condições atuais não podem ser economicamente readmitidas ou mesmo escoadas, despejadas em terras distantes, como outrora, onde possam ser úteis. A perversa especificidade desse conceito admitido como classificador fidedigno às realidades econômica e social vigentes (que supõem pessoas realmente inúteis), é que não inspiram a menor esperança de melhora. Nessa condição se está definitivamente fora do sistema de classes: não há papel a desempenhar ou mobilidade social possível. Ser um underclass, um supérfluo, não é o mesmo que estar sob a condição social anômala e incidental de desemprego - para 
a qual a norma e a própria possibilidade de reintegração é o emprego. Um underclass é em última análise um indesejável que não se pode incorporar ou deportar, o membro de uma comunidade de pessoas desnecessárias cujo melhor destino, do ponto de vista econômico, social e mesmo político, seria não a reintegração (a um sistema de mercado que se liberta inclusive dos cálculos humanos), mas antes o desparecimento de uma vez por todas.

Numa sociedade de consumidores incondicionalmente orientada pelo progresso econômico, um underclass é certamente um "cidadão" (na verdade um pseudocidadão) com quem não se pode contar para a superação dos períodos críticos e decisivos de recessão econômica, ou mesmo para retornar à normalidade em face de atentados terroristas, cataclismos e outras desgraças sociais menos expressivas. Uma normalidade que em todos os casos somente se retoma (como George W. Bush indicou com uma objetividade ímpar) a partir da volta às compras, a atividade normal em relação a qual os mais extraordinários e dramáticos acontecimentos não representam mais do que breves interrupções. Daí que "nos livros de contabilidade de uma sociedade de consumo os pobres" que "entram na coluna dos débitos" (BAUMAN 2008, p. 160) também se enquadram, ou na verdade realmente são o alvo privilegiado da categoria intencionalmente vaga de subclasse.

Todavia, mais do que não-consumidores esses membros da subclasse também são - o que é acentuadamente mais grave para uma sociedade de consumo - "consumidores falhos”, para não dizer parasitas sociais. Pessoas propensas a depender ou efetivamente dependentes do auxílio, antes compreendido em temos de proteção, que em princípio definia a missão do Estado social. Este Estado protetor que 
especialmente nos países desenvolvidos está sendo mudado em Estado terapêutico - o mesmo que por influxo da nova economia reconhece nos consumidores os principais ativos (cidadãos) dos quais pode dispor - tem de ceder aos poucos à tendência econômica de privatizar e criminalizar os onerosos problemas outrora definidos como sociais ${ }^{15}$. Portanto o termo subclasse em última análise

[...] implica uma sociedade que é tudo menos hospitaleira e atenciosa com todos, uma sociedade atenta, em vez disso, ao lembrete de Carl Schmitt de que o traço definidor da soberania é a prerrogativa de eximir, excluir e colocar de lado uma categoria de pessoas às quais a lei é aplicada mediante a negação ou revogação de sua aplicação." (BAUMAN 2008, p. 156)

Com efeito, a justaposição política acima referida entre o cidadão exemplar e o consumidor zeloso - indivíduos com quem se pode contar nos momentos de crise e sobretudo de crescimento -, seguida e correlata à equação econômica entre o consumidor falho e o tipo humano indesejável (o underclass com quem não se pode contar em circunstância econômica alguma) é demasiado obstinada para ser negligenciada. A subclasse implica determinações econômicas que reverberam de modo decisivo no ordenamento político. É abandonando a subclasse à própria sorte ou excluindo-a do sistema de proteção que o Estado clínico "trata" e capitaliza o problema social da pobreza e da superfluidade degradante ante os olhos de uma poderosa economia. A crermos nas palavras de Carl Schmitt evocadas

\footnotetext{
15 "Numa sociedade de consumidores, há 'consumidores falhos', pessoas carentes de recursos para adicionar à capacidade do mercado de consumo, criando outro tipo de existência à qual a indústria orientada pelo consumo não pode responder, e que ela não pode lucrativamente colonizar. Os consumidores são os principais recursos de uma sociedade de consumo, os consumidores falhos são os seus passivos mais fatigantes e dispendiosos." (BAUMAN 2010b, p. 155)
} 
por Zygmunt Bauman, o poder de "eximir, excluir e colocar de lado uma categoria de pessoas às quais a lei é aplicada mediante a negação ou revogação de sua aplicação" é a derradeira prova da sobreposição do econômico sobre o político.

Devemos recordar nesse caso as recorrentes e insistentes observações em que Bauman enfatiza que a expressão subclasse lembra um agregado de seres humanos que, desenganados pela própria política (como nos sentimos tentados a dizer), foram declarados e efetivamente postos fora dos limites do sistema de classes, com poucas chances e seguramente sem qualquer necessidade de serem reintegradas ao sistema social. Pessoas supérfluas, inúteis e parasitárias que mesmo na ausência de um sedutor expediente totalitário de extirpação dos supérfluos, não escapam à prerrogativa com que Carl Schmitt julgou poder localizar a soberania política em toda parte.

Se a exclusão econômica, e a um só tempo social e política, circunscreve uma pena à subclasse, que inclusive é bastante dura e situada além da redenção, não há como negar que o cenário atual pende para a criminalização da marginalidade social .

Em Vidas desperdiçadas Bauman sustenta que em sua formulação econômica e política, o problema da superpopulação é uma "ficção atuarial" que, de um modo um tanto quanto turvo, expressa o tratamento da questão social pela via da exclusão; o traço definidor e a prerrogativa do poder soberano agora situado sobre a esfera econômica. Para Bauman, "superpopulação" é a expressão destinada a excluir e a condenar um certo conjunto de pessoas cujo número, ao contrário de fomentar os índices econômicos, tornam muito mais custosa a obtenção, para não dizer a elevação, dos indicadores de seu funcionamento regular ou adequado. 
Em outros termos, excesso populacional é designação para aquela parcela da população que já não pode ser reintegrada aos padrões de vida normais e reconduzida para a categoria do membros 'úteis' da sociedade. No problema do excesso populacional resta a pressuposição de que "sempre há um número demasiado deles. 'Eles' são os sujeitos dos quais deveria haver menos - ou ainda melhor, não deveria haver nenhum. E nuca há um número suficiente de nós. 'Nós são as pessoas das quais deveria haver mais"” (BAUMAN 2010b, p. 154. Grifos nossos)

Mas essa variedade histórica de refugo humano aponta para um tipo de poder soberano, o econômico, que apesar de se prestar à compreensão nos moldes teóricos fornecidos por Carl Schmitt (particularmente em função do princípio de exceção), extrapola os seus limites no que se refere à ideia de escolha das vítimas legítimas em virtude da ordem que se planeja construir. Pois ao contrário da exclusão proposital de certas vítimas da proteção da lei a partir do poder soberano de matriz schmittiana, as vítimas da subclasse, que em última análise são excluídas por determinações econômicas, "são, em vez disso, 'baixas colaterais' inesperadas, não intencionais e não planejadas do progresso econômico." (BAUMAN 2004a, p. 53).

Essa colateralidade evoca portanto a paradoxal ordem $\mathrm{da}$ contingência, aquela espécie de governo do caos em que ninguém dá as ordens e nem tampouco assume a responsabilidade, que não escolhe as vítimas mas engendra riscos incontroláveis e lança a vida humana numa precariedade estrutural. Uma “ordem” refratária à estabilidade e ao planejamento das trajetórias de vida, quer elas sejam consideradas individual ou coletivamente.

Abstract: The sociological analysis about some of the most important impli- 
cations of the recent flexible capitalist system in any way wrong target when binding the general problem of systemic instability to the lack of living conditions, social risks (that this lack is related) and the promotion of a shortterm mentality. After all, these phenomena are witnessed within the particular job, and the policy area in general. Next to the science and technology the economy is one of the main factors that modern institutionalize risk in the social scale. For our approach, developed with facilities in the thoughts of Ulrich Beck, Zygmunt Bauman and Richard Sennett, what matters is that in addition to business opportunities economic risks define the newest tasks of the political sphere socially displaced by the divorce proceedings with the power.

Keywords: policy; economy; flexible capitalism; risk.

\section{REFERÊNCIAS}

BAUMAN, Zygmunt.44 Cartas do mundo líquido moderno. Rio de Janeiro: Jorge Zahar Editor, $2011 \mathrm{~b}$.

- A ética é possível num mundo de consumidores? Rio de Janeiro: Jorge Zahar Editor, 2011a.

- Amor líquido. Sobre a fragilidade dos laços humanos. Rio de Janeiro: Jorge Zahar Editor, 2004b.

- Capitalismo parasitário e outros temas contemporâneos. Rio de Janeiro: Jorge Zahar Editor, 2010a.

- Confiança e medo na cidade. Rio de Janeiro: Jorge Zahar Editor, 2009.

. Em busca da política. Rio de Janeiro: Jorge Zahar Editor, 2000.

- Globalização - as consequências humanas. Rio de Janeiro: Jorge Zahar Editor, 1999.

- Legisladores e intérpretes. Rio de Janeiro: Jorge Zahar Editor, 2010c. 
- Modernidade líquida. Rio de Janeiro: Jorge Zahar Editor, 2001.

- Vida a crédito. Rio de Janeiro: Jorge Zahar Editor, $2010 \mathrm{~b}$.

- Vidas desperdiçadas. Rio de Janeiro: Jorge Zahar Editor, 2004a.

- Vida em fragmentos- sobre a ética pós-moderna. Rio de Janeiro: Jorge Zahar Editor, 2011c.

- Vida para consumo - a transformação das pessoas em mercadorias. Rio de

Janeiro: Jorge Zahar Editor, 2008.

BECK, Ulrich. Sociedade de risco. São Paulo: Editora 34, 2010.

. Liberdade ou capitalismo. São Paulo: Editora Unesp, 2002.

BELL, Daniel. Las contradiciones culturales del capitalismo. México: Alianza Editorial, 1994.

FOUCAULT, Michel. Nascimento da biopolítica. São Paulo: Martins Fontes, 2008.

- Segurança, território e população. São Paulo: Martins Fontes, 2005.

GIDDENS, Antony. Modernidade e identidade. Rio de Janeiro: Jorge Zahar Editor Ltda., 2002.

LIPOVETSKY. Gilles. A cultura mundo. Resposta a uma sociedade desorientada. São Paulo: Companhia das Letras, 
2011.

. Felicidade paradoxal. São Paulo: Companhia das Letras, 2007.

- O império do efêmero. A moda e seus destinos nas sociedades modernas. São Paulo: Companhia de Bolso, 2009.

SENNETT, Richard. A corrosão do caráter - consequências pessoais do trabalho no nova capitalismo. Rio de Janeiro, São Paulo: Editora Record, 2011.

- A nova cultura do capitalismo. Rio de Janeiro, São Paulo: Editora Record, 2006.

WEBER, Marx. A ética protestante e o espírito do capitalismo. 2 ed. rev. São Paulo: Cengage Learning, 2001.

. Conceitos básicos de sociologia. 4 ed. São Paulo: Centauro Editora, 2005. 